\title{
Low serum secretory immunoglobulin A level and sense of coherence score at an early gestational stage as indicators for subsequent threatened premature birth
}

\author{
Naomi Sekizuka · Akemi Sakai · Keiko Shimada • \\ Noriko Tabuchi · Yukie Kameda · Hiroyuki Nakamura
}

Received: 24 August 2008/Accepted: 10 June 2009/Published online: 7 July 2009

(C) The Japanese Society for Hygiene 2009

\begin{abstract}
Objectives The purpose of this study was to assess the validity of the candidate indicators secretory immunoglobulin A (s-IgA) and sense of coherence (SOC) as predictors of threatened premature birth.

Methods This was a panel study conducted on women in their first and latter half of pregnancy during survey period. The survey period was from December 2005 to June 2006 and from December 2007 to June 2008. The women enrolled in the study were asked to complete the survey questionnaire and provide blood samples for the determinations of physiological indicators. The questionnaire consisted of questions related to the stress perception scale (SPS), SOC score as an indicator of modifiers of stress, demographic data, complications in a previous pregnancy, and the course of the current pregnancy. We used s-IgA and high-sensitivity C-reactive protein as a physiological stress indicator and a marker of infection, respectively. Seventy-two eligible subjects were included in the analysis. Results Twenty-eight (38.9\%) subjects had undergone treatment for threatened premature birth, and $44(61.1 \%)$ subjects had not. In the logistic analysis, we set the course of pregnancy as a dependent variable, and age, birth
\end{abstract}

N. Sekizuka $(\bowtie) \cdot$ A. Sakai · K. Shimada $\cdot$ N. Tabuchi

Y. Kameda

Department of Health Sciences,

Graduate School of Medical Science,

Kanazawa University, 5-11-80 Kodatsuno,

Kanazawa 920-0942, Japan

e-mail: sekky@mhs.mp.kanazawa-u.ac.jp

H. Nakamura

Department of Environmental and Preventive Medicine,

Graduate School of Medical Science,

Kanazawa University, Kanazawa, Japan history, smoking habits, a history of miscarriage, premature birth or threatened premature birth, SPS, SOC, and s-IgA in the first half of pregnancy as independent variables. We found that low serum s-IgA levels and low SOC scores in the first half of pregnancy were associated with threatened premature birth.

Conclusions Our results suggest that low serum s-IgA level and SOC score at an early gestational stage are significant indicators for a threatened premature birth.

Keywords Pregnant women .

Secretory immunoglobulin A - Sense of coherence .

Stress $\cdot$ Threatened premature birth

\section{Introduction}

Many studies have reported that stress in a variety of forms affects pregnancy outcome. For example, miscarriage [1], premature birth [2,3], low-birth-weight infants [4, 5], pregnancy-induced hypertension [6], depression during the pregnancy period [7], and postpartum depression [8-10] have been reported as stress-related peripartum abnormalities. Among these, premature birth and low-birth-weight infants have been identified as the main stress-related pregnancy outcomes [11]. Previous studies have found that the risk of premature birth is higher in pregnant women who experience stress in their daily lives [12-15]. Alternatively, it has also been reported that psychosocial stress during the pregnancy period is not necessarily related to premature birth [16-18].

The reaction to stress differs because stress is a subjective phenomenon and depends largely on an individual's perception of stress and his/her ability to cope with it [19]. This subjectivity has lead many researchers in the field of 
stress to focus on searching for physiological indicators that would enable stress to be estimated objectively. Accordingly, several studies have reported on an association between premature birth and corticotrophin-releasing hormone (CRH) [20-23]. One study [22] found that women with high $\mathrm{CRH}$ levels at 28-30 weeks of gestation delivered earlier than women with lower CRH levels. Hobel [24] showed that changes in CRH between 18-20 weeks of gestation and 28-30 weeks of gestation are associated with stress levels at 18-20 weeks of gestation, suggesting that maternal stress and $\mathrm{CRH}$ levels are potential markers for the patient at risk for preterm birth. However, the factors associated with $\mathrm{CRH}$ have not been clarified [25], and it has not yet been established whether $\mathrm{CRH}$ causes preterm delivery [26]. Secretory immunoglobulin A (s-IgA), which is a key regulator that forms a part of the biological defense system and is secreted in large amounts in situations of sudden stress, is also used as a physiological indicator for estimating stress objectively [27]. However, low s-IgA values under chronic stress conditions [28], a negative correlation with the extent of unpleasantness in the events that occurred during the previous 2 weeks [29], low s-IgA values during a negative mood compared to a positive mood [30], and a negative correlation between s-IgA and a tendency to develop depression [31] have also been reported. Volkmann et al. [32] suggest that basal s-IgA levels of healthy young adults predict stress-related susceptibility to ill health. These findings mean that the amount of s-IgA secretion reflects the state of stress and health status.

Several published studies focused on the ability to cope with stress, which affects health status as a stress reaction [33-37]. Sjöström et al. [33] used the sense of coherence (SOC) scale as the stress coping ability indicator in a study involving 120 pregnant women in Stockholm. They reported that each woman's degree of SOC was a strong predictor for well-being, and the stronger the SOC, the better the well-being, with less anxiety and depression.

Given this background, we have designed a study to assess the ability of the candidate indicators s-IgA and SOC at an early gestational stage to predict threatened premature birth, focusing on the relationship between stress and premature birth.

\section{Subjects and methods}

\section{Subjects}

We obtained consent from three facilities (one public hospital and two private clinics) to approach pregnant women attending their clinics at two time points: December 2005 and December 2007. The number of eligible women was estimated to be 270 , and $110(40.7 \%)$ of these were enrolled in the study in the order of consultations after giving informed consent. The subjects had visited the facilities for regular health check-up once a month and had not been provided any treatment for threatened abortion during the first half of pregnancy.

\section{Methods}

The survey period was from December 2005 to June 2006 and from December 2007 to June 2008. This was a panel study and included a questionnaire survey and blood collection during regular health check-ups in the first and latter half of pregnancy. The survey questionnaire was completed by the participants, who also supplied blood samples for the determination of blood physiological indicators. The completed questionnaires were kept in a sealed envelope or collected by mail. Of the 110 pregnant women initially enrolled, 23 were excluded due to medical reasons [miscarriage $(n=3)$, multiple pregnancy $(n=1)$, habitual abortion $(n=1)$, recurrent abortion $(n=2)$, medical complications ( $n=5$ : abnormal thyroid function, $n=3$; asthma, $n=2)$ ] and other factors [change in hospital $(n=6)$, declined participation during the course of the study $(n=4)$, and invalid responses $(n=3)$. (Two subjects were overlapping.) In addition, 15 subjects who had high levels of high-sensitivity C-reactive protein (hsCRP) ( $\geq$ mean value \pm SD) in the first half of pregnancy and diagnosed infection were excluded as infections are deemed to be the main risk factor for premature birth [38], and elevated CRP concentrations in early pregnancy are associated with an increased risk of preterm delivery [39]. The case of vaginal infection included candida $(n=4)$, chlamydia $(n=3)$, bacterial vaginosis $(n=6)$, Group B streptcoccus $(n=4)$, and chorioamnionitis $(n=1)$. (Three subjects were overlapping.) Ultimately, 72 subjects (26.7\%) were included in the analysis. This study was conducted with the approval of the ethical committees of Kanazawa University Graduate School of Medical Science (approval number 22) and the medical facilities that cooperated with this study (approval number 99).

\section{Questionnaire survey and data collection}

The questionnaire that was given to all participants in their first half of pregnancy comprised questions relating to the stress perception scale (SPS), a shortened version of the SOC scale, demographic data, complications in previous pregnancies, and the course of the current pregnancy. The questionnaire used in the latter half of pregnancy consisted of questions relating to the SPS scale, a shortened version of the SOC, and the course of the current pregnancy. Demographic data included age, 
birth history, complications, and smoking habits. Complications in previous pregnancies were included such complications miscarriage or premature birth. The course of pregnancy was surveyed whether or not any treatment had been provided for threatened premature birth during the course of the current pregnancy. When necessary, the current course of pregnancy and the presence of infection were assessed using individual medical charts.

The SPS and SOC were set as explanatory variables and used as stress perception and stress coping ability, respectively. The SPS evaluated stress perception in seven areas of stress (work, family, neighborhood relations, as well as living-, social-, financial-, and health-related situations) [40]. Each parameter was evaluated on a scale of 11 (0-10 points), where 0 points represented a situation with no stress and 10 points represented the strongest feeling of stress (the higher the score, the stronger the degree of stress experienced.) In this study, the total sum of the seven areas of stress was calculated and evaluated. Cronbach's coefficient alpha of the seven SPS parameters in the first and latter half of pregnancy was 0.70 and 0.82 , respectively.

The SOC is a conceptually developed measure of a person's ability to maintain health and to cope with stress, It was devised by Antonovsky [41], based on the salutogenetic model, and comprises 29 parameters that are in turn based on a subordinate concept of three parameters: comprehensibility, manageability and meaningfulness [42]. The responses to each question are rated on a seven-point scale (score 1-7), and the total score is calculated. A higher total score indicates that the individual is less likely to undergo stress even when facing diverse stressful stimuli. In this study, we used the shortened Japanese version of the SOC scale by Yamazaki [43]. The reliability of the modified shortened version has been confirmed by previous research, and a systematic review of 127 studies yielded a Cronbach's coefficient alpha of $0.70-0.92$ [44]. Cronbach's coefficient alpha values of the 13 SOC parameters used in this study were 0.84 and 0.86 in the first and latter half of pregnancy, respectively.

\section{Determination of physiological indicators}

The s-IgA was used as the physiological stress indicator, and we used hsCRP as a marker of infection. Both indicators were measured from serum samples of the subjects. Blood (9-ml samples) was collected between 9 and 12 a.m and, on the same day, the collected samples were separated by centrifugation and stored at below $-80^{\circ} \mathrm{C}$ at the same institute until assay to maintain the stability of the determined indicators. Measurements were performed by an experienced technologist and performed in duplicate.
While s-IgA was determined by an enzymatic immunoassay using a s-IgA measuring kit (MBL Co, Japan), hsCRP was quantified by Latex nephelometry using N-Latex CRPII (Dade Behring, Deerfield, IL).

Analysis methods

S-IgA values were transformed to a logarithmic scale to obtain a normal distribution.

The paired $t$ test and Pearson correlation coefficient were used to calculate the relationship between SPS scores in the first half of pregnancy and those in the latter half of pregnancy. In the same way, the paired $t$ test and Pearson correlation coefficient were used to assess the SOC scores and s-IgA in the first half of pregnancy and those in the latter half of pregnancy. We calculated cut-off points by receiver operating characteristic (ROC) analysis to assess the level of SPS, SOC and s-IgA that may predict threatened premature birth.

Associations between demographic data (age, birth history, smoking habits, a history of miscarriage, premature birth or threatened premature birth in the past) and the course of pregnancy (threatened premature birth or nonthreatened premature birth) were analyzed using the chisquare test.

The mean values of the SPS and SOC scores were compared among three age groups $(\leq 24, \geq 25, \leq 34, \geq 35$ years) using one-way analysis of variance (ANOVA). The SPS and SOC scores were compared between primipara and multipara using Student's $t$ test. S-IgA levels were compared among three age groups $(\leq 24, \geq 25, \leq 34, \geq 35$ years) using Kruskai-Wallis $H$ test. The s-IgA levels were compared between primipara and multipara using MannWhitney $U$ test. Student's $t$ test was used for analyzing the differences in the mean values of s-IgA levels between in the high and low SPS groups and between the high and low SOC groups.

The percentage of pregnant women with threatened premature birth was compared between the high and low SPS groups, between the high and low SOC groups, and between in the high and low s-IgA groups using the chisquare test. Logistic analysis was performed for the multivariate analysis to clarify the association between stress and threatened premature birth. We set the course of pregnancy as a dependent variable, and age, birth history, smoking habits, a history of miscarriage, premature birth or threatened premature birth in the past, SPS, SOC, and s-IgA in the first half of pregnancy as independent variables. The Statistical Package for Social Sciences ver. 16.0 for Windows (SPSS, Chicago, IL) was used for the analysis, and $p<0.05$ was regarded as being statistically significant in all tests. 


\section{Results}

Characteristics of the subjects

The mean age \pm SD of the study cohort was $30.0 \pm 5.4$ years (range 17-44 years), the mean length of the survey periods in the first and latter half of pregnancy were $12.0 \pm$ 0.6 and $30.0 \pm 0.2$ weeks, respectively, and the birth history was primipara and multipara in $36(50.0 \%)$ and $36(50.0 \%)$ subjects, respectively. Eight $(11.1 \%)$ subjects were current smokers, $22(30.6 \%)$ had a history of smoking but quit smoking when they became pregnant (or realized pregnancy), and $42(58.3 \%)$ had never smoked. Thirteen subjects $(18.1 \%)$ had a history of miscarriage, premature birth, or threatened premature birth in the course of previous pregnancies. Twenty-eight $(38.9 \%)$ subjects had undergone treatment for threatened premature birth in the course of the current pregnancy, and $44(61.1 \%)$ subjects had not.

We did not observe any significant differences in the percentages of pregnant women with threatened premature birth in the course of the current pregnancy between primipara and multipara, among the three age groups $(<25$, 25-34, and $\geq 35$ years), among the three groups for smoking habits (current smokers, history of smoking but had quit smoking, and had never smoked), or between pregnant women who has a history of miscarriage, premature birth, or threatened premature birth in the course of previous pregnancy and those who did not (Table 1).

Table 1 Association between demographic data and the course of pregnancy

\begin{tabular}{|c|c|c|c|c|}
\hline Variable & $n$ & $\begin{array}{l}\text { Threatened } \\
\text { premature birth, } \\
n=28(\%)\end{array}$ & $\begin{array}{l}\text { Non-threatened } \\
\text { premature birth, } \\
n=44(\%)\end{array}$ & $p$ value \\
\hline \multicolumn{5}{|l|}{ Age (years) } \\
\hline$\leq 24$ & 9 & $5(55.6)$ & $4(44.4)$ & \multirow[t]{3}{*}{0.531} \\
\hline$\geq 25, \leq 34$ & 51 & $19(37.3)$ & $32(62.7)$ & \\
\hline$\geq 35$ & 12 & $4(33.7)$ & $8(66.7)$ & \\
\hline \multicolumn{5}{|l|}{ Birth history } \\
\hline Primipara & 36 & $14(38.9)$ & $22(61.1)$ & \multirow[t]{2}{*}{0.595} \\
\hline Multipara & 36 & $14(38.9)$ & $22(61.1)$ & \\
\hline \multicolumn{5}{|l|}{ Smoking habits } \\
\hline Current smokers & 8 & $3(37.5)$ & $5(62.5)$ & \multirow[t]{2}{*}{0.374} \\
\hline $\begin{array}{l}\text { Has a history of } \\
\text { smoking but quit } \\
\text { smoking }\end{array}$ & 22 & $6(27.2)$ & $16(72.7)$ & \\
\hline Never smoked & 42 & $19(45.2)$ & $23(54.8)$ & \\
\hline \multicolumn{5}{|c|}{$\begin{array}{l}\text { A history of miscarriage, premature birth, or threatened premature } \\
\text { birth in the past }\end{array}$} \\
\hline No & 59 & $24(40.7)$ & $35(59.3)$ & \multirow[t]{2}{*}{0.369} \\
\hline Yes & 13 & $4(30.8)$ & $9(69.2)$ & \\
\hline
\end{tabular}

$* p$ value by chi-square test
Association between the level of s-IgA and SPS or SOC

Mean values of s-IgA \pm SD (range) in the first and latter half of pregnancy were $15.5 \pm 5.0(6.9-33.9 \mu \mathrm{g} / \mathrm{ml})$ and $22.1 \pm 7.8 \mu \mathrm{g} / \mathrm{ml} \quad(10.4-57.9 \mu \mathrm{g} / \mathrm{ml})$, respectively. The s-IgA levels were significantly higher in the latter half of pregnancy than in the first half $(p<0.001)$. We observed a significant strong positive correlation $(r=0.740$, $p<0.001$ ) between the s-IgA levels of pregnant women in the first half of pregnancy and that in the latter half of pregnancy. The $\log$ s-IgA values in the first half of pregnancy were classified into low $(<1.18, n=38)$ and high $(\geq 1.18, n=34)$ groups.

Mean SPS scores \pm SD in the first and latter half of pregnancy were $21.1 \pm 10.4$ and $21.6 \pm 11.6$, respectively. The differences between SPS scores in the first half of pregnancy and those in the latter half of pregnancy were not significant, but there was a significant positive correlation between the SPS scores in the first half of pregnancy and those in the latter half $(r=0.651, p<0.001)$. SPS scores in the first half of pregnancy were classified into two groups: low $(<22, n=32)$ and high $(\geq 22, n=40)$.

Mean SOC scores \pm SD in the first and latter half of pregnancy were $60.7 \pm 11.8$ and $59.5 \pm 10.9$, respectively. The differences between SOC scores in the first half of pregnancy and those in the latter half of pregnancy were not significant, but there was a significant strong positive correlation between the SOC scores in the first half of pregnancy and those in the latter half $(r=0.783$, $p<0.001)$. SOC scores in the first half of pregnancy were classified into two groups: low $(<60, n=32)$ and high $(\geq 60, n=40)$.

Table 2 presents the results of our comparison of SPS scores, SOC scores, and s-IgA levels. There were no significant differences in SPS scores, SOC scores, and the s-IgA levels between primipara and multipara, or among the three age groups $(<25,25-34$, and $\geq 35$ years $)$. The data were analyzed without the classification of birth history or age. The s-IgA level in the first half of pregnancy was lower in the high SPS group $(15.2 \pm 6.1 \mu \mathrm{g} / \mathrm{ml})$ than that in the low SPS group $(15.8 \pm 3.2 \mu \mathrm{g} / \mathrm{ml})$, but the difference was not significant $(p=0.101)$. The s-IgA level determined in the first half of pregnancy was lower in the low SOC group $(14.4 \pm 4.7 \mu \mathrm{g} / \mathrm{ml})$ than in the high SOC group $(16.3 \pm 5.1 \mu \mathrm{g} / \mathrm{ml})$, but the difference was not significant $(p=0.080)$.

Association between s-IgA, SPS, SOC, and threatened premature birth

Although a higher percentage of threatened premature birth was observed in the high SPS group (45.0\%) than in the low SPS group (31.3\%), the difference was not significant 
Table 2 Scores of SPS, SOC and the level of s-IgA according to age or birth history

\begin{tabular}{|c|c|c|c|c|c|c|c|c|}
\hline \multirow[t]{2}{*}{ Variable } & \multirow[t]{2}{*}{ Period } & \multicolumn{4}{|c|}{ Age, years $(n)$} & \multicolumn{3}{|l|}{ Birth history $(n)$} \\
\hline & & $\leq 24(9)$ & $\geq 25, \leq 34(51)$ & $\geq 35(12)$ & $p$ value & Primipara (36) & Multipara (36) & $p$ value \\
\hline \multirow[t]{2}{*}{ SPS (score) } & The first half of pregnancy & $23.4 \pm 12.2$ & $22.7 \pm 10.3$ & $24.5 \pm 10.3$ & $0.864^{\mathrm{a}}$ & $24.1 \pm 10.5$ & $22.1 \pm 10.4$ & $0.415^{\mathrm{b}}$ \\
\hline & The latter half of pregnancy & $15.7 \pm 7.6$ & $19.5 \pm 12.0$ & $28.6 \pm 9.2$ & $0.152^{\mathrm{a}}$ & $19.5 \pm 10.3$ & $21.7 \pm 13.0$ & $0.584^{\mathrm{b}}$ \\
\hline \multirow[t]{2}{*}{ SOC (score) } & The first half of pregnancy & $53.6 \pm 13.5$ & $61.2 \pm 10.2$ & $61.6 \pm 11.2$ & $0.099^{\mathrm{a}}$ & $58.5 \pm 11.6$ & $62.9 \pm 10.5$ & $0.392^{\mathrm{b}}$ \\
\hline & The latter half of pregnancy & $54.7 \pm 6.6$ & $60.8 \pm 9.8$ & $57.0 \pm 17.0$ & $0.495^{\mathrm{a}}$ & $57.9 \pm 12.0$ & $61.1 \pm 9.8$ & $0.392^{\mathrm{b}}$ \\
\hline \multirow[t]{2}{*}{$\mathrm{s}-\operatorname{IgA}(\mu \mathrm{g} / \mathrm{ml})$} & The first half of pregnancy & $13.9 \pm 4.1$ & $15.6 \pm 4.8$ & $16.2 \pm 6.3$ & $0.577^{\mathrm{c}}$ & $15.1 \pm 6.0$ & $15.8 \pm 3.8$ & $0.596^{\mathrm{d}}$ \\
\hline & The latter half of pregnancy & $21.0 \pm 5.5$ & $22.5 \pm 8.7$ & $21.6 \pm 5.7$ & $0.886^{\mathrm{c}}$ & $21.0 \pm 6.7$ & $23.2 \pm 8.7$ & $0.330^{\mathrm{d}}$ \\
\hline
\end{tabular}

SPS stress perception scale, $S O C$ sense of coherence, $s$-IgA secretory immunoglobulin A

Values are given as the mean $\pm \mathrm{SD}$

${ }^{a} p$ value by one-way analysis of variance

${ }^{\mathrm{b}} p$ value by Student's $t$ test

${ }^{\text {c }} p$ value by Kruskal-Wallis $H$ test

${ }^{\mathrm{d}} p$ value by Mann-Whitney $U$ test

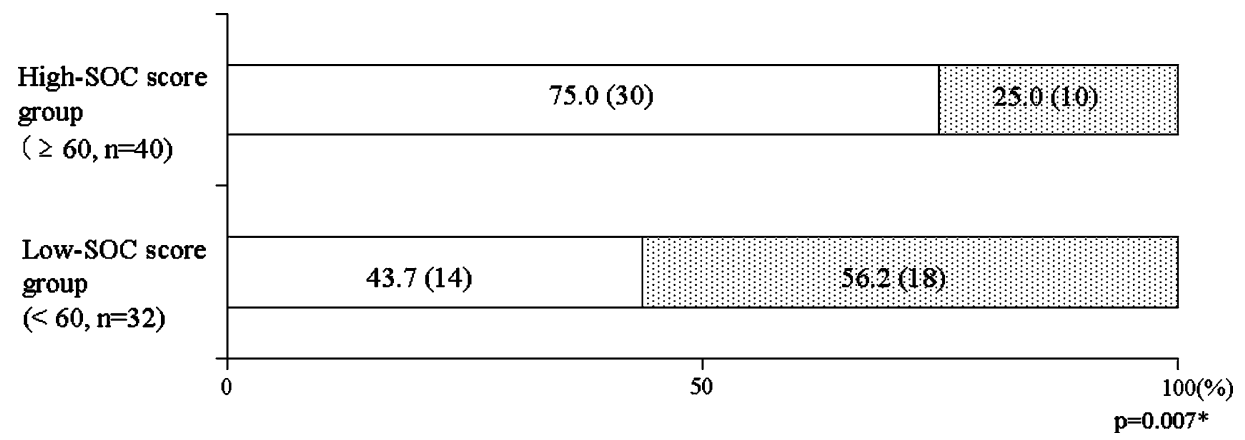

Fig. 1 Association between the sense of coherence (SOC) score in the first half of pregnancy and the course of pregnancy. Values are given as percentages, and values in parenthesis are the actual number.
Asterisk indicates significance as calculated by the $\chi^{2}$-test. Open bar Non-threatened premature birth, stippled bar threatened premature birth

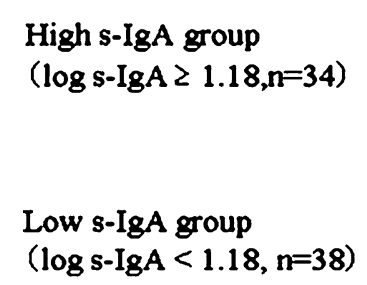

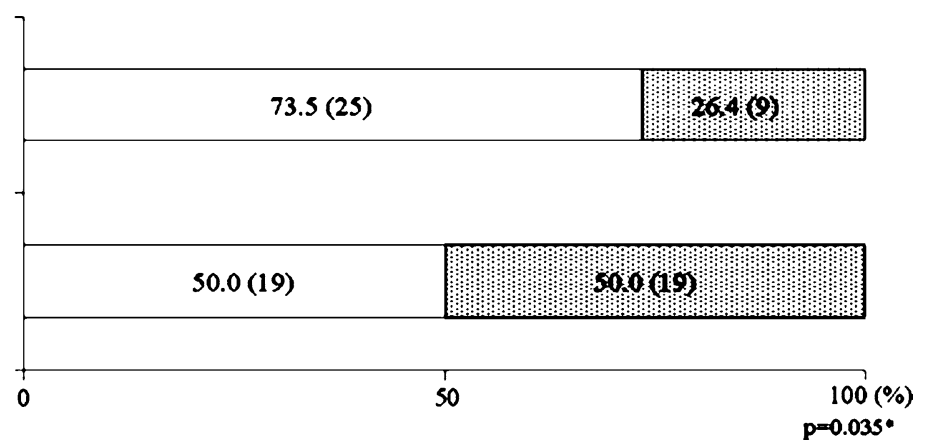

Fig. 2 Association between secretory immunoglobulin-A ( $s-\operatorname{Ig} A)$ levels in the first half of pregnancy and the course of pregnancy. Values are given as percentages, and values in parenthesis are the

$(p=0.172)$. In contrast, the percentage of threatened premature birth was significantly higher in the low SOC group than in the high SOC group (Fig. 1), and significantly higher in the low s-IgA group than in the high s-IgA group (Fig. 2). The logistic analysis demonstrated that low SOC scores and low s-IgA levels were associated with threatened premature birth (Table 3). actual number. Asterisk indicates significance as calculated by the $\chi^{2}$-test. Open bar Non-threatened premature birth, stippled bar threatened premature birth

\section{Discussion}

The neuroendocrinological and immunological mechanisms of biological reactions against stress comprise the physiological changes of the nervous, endocrine, and immune systems (stimulation of the autonomous nervous system, promotion of the secretion of endocrine hormones, 
Table 3 Logistic regression model for threatened premature birth $(n=72)$

\begin{tabular}{|c|c|c|c|c|}
\hline Variable & Regression & $p$ value & OR & $95 \% \mathrm{CI}$ \\
\hline \multicolumn{5}{|l|}{ Age (years) ${ }^{\mathrm{a}}$} \\
\hline$\geq 25, \leq 34 / \leq 24$ & 0.772 & 0.471 & 2.164 & $0.265-17.640$ \\
\hline$\geq 35 / \leq 24$ & 0.291 & 0.805 & 1.338 & $0.134-13.381$ \\
\hline Parity $^{\mathrm{b}}$ & 1.419 & 0.071 & 4.131 & $0.886-19.272$ \\
\hline \multicolumn{5}{|l|}{ Smoking $^{c}$} \\
\hline Has a history of smoking but quit smoking/never smoked & -1.491 & 0.064 & 0.225 & $0.047-1.088$ \\
\hline Current smokers/never smoked & 1.015 & 0.417 & 2.759 & $0.238-31.960$ \\
\hline Miscarriage or premature birth $^{\mathrm{d}}$ & -0.153 & 0.852 & 0.858 & $0.173-4.262$ \\
\hline $\mathrm{SPS}^{\mathrm{e}}$ & -1.213 & 0.119 & 0.297 & $0.065-1.364$ \\
\hline $\operatorname{SOC}^{\mathrm{f}}$ & -0.157 & 0.000 & 0.855 & $0.784-0.932$ \\
\hline $\mathrm{s}-\operatorname{Ig} \mathrm{A}^{\mathrm{g}}$ & -1.497 & 0.028 & 0.224 & $0.059-0.849$ \\
\hline Coefficient & 9.276 & 0.001 & & \\
\hline
\end{tabular}

OR odds ratio, $95 \%$ CI $95 \%$ confidence intervals

${ }^{\text {a }}$ Age $(1, \leq 24 ; 2, \geq 25, \leq 34 ; 3, \geq 35$ years)

b Parity ( $1=$ primipara, $2=$ multipara $)$

c Smoking, smoking habits $(1=$ never smoked, $2=$ has a history of smoking but quit smoking, $3=$ current smokers $)$

${ }^{\mathrm{d}}$ Miscarriage or premature birth, a history of miscarriage, premature birth or threatened premature birth $(1=$ not yet, $2=$ have past history)

e $\operatorname{SPS}(1=$ low score, $<22 ; 2=$ high score, $\geq 22)$

${ }^{\mathrm{f}} \mathrm{SOC}$, Sense of coherence score

g $\operatorname{s-IgA}(1=$ low level, $<1.18 ; 2=$ high level, $\geq 1.18)$

and a decrease in the activity of the cells of the immune system), and the physiological changes brought about by these three systems affect and modulate each other's functions [45]. Among the various immune reactions, we used s-IgA level as an indicator to evaluate stress objectively. Only a few studies have shown an association between serum s-IgA levels and stress in pregnant women. Thus, there is only a limited amount of basic data currently available in this area, and no cut-off point for the determination of high or low stress had yet been determined. Ichikawa [46] reported that maternal serum s-IgA level increased as the last stage of pregnancy approached in comparison to the first stage of pregnancy. The changes in s$\operatorname{IgA}$ levels between the first and latter half of pregnancy that we observed in our study are in good agreement with those reported by Ichikawa [46]. Several studies have examined s-IgA levels in salivary or breast-milk of peripartum women. Annie et al. [47] determined the amount of salivary s-IgA during pregnancy and that anxiety at the time of birth had a suppressive effect on s-IgA levels. The study on the effects of stress on parturient women [48] reported a positive correlation between the length of time spent with family and s-IgA levels $2 \mathrm{~h}$ before parturition and that the presence of family can be considered to be a factor that alleviates stress in parturient women. These studies all demonstrated an association between low s-IgA levels and stress in peripartum women. In terms of SOC score,
Sjöström et al. [33] reported that a woman's degree of SOC was a strong predictor of psychological well-being. In Japan, two studies [36, 37] have reported an association between the SOC score of pregnant women and their mental health status, including stress. Our results showing that low s-IgA levels and SOC scores, as indicators of modifiers of stress, were associated with subsequent threatened premature birth suggest that threatened premature birth is produced by severe stress during pregnancy. Previous studies have also demonstrated that the state of stress during the early stage of pregnancy affects the course of pregnancy and the health of the fetus [49]. However, few studies have objectively demonstrated an association between stress and the course of pregnancy from a physiological viewpoint. Our results showing a low s-IgA level in pregnant women with threatened premature birth suggest that immunological disturbances associated with stress account for threatened premature birth. This hypothesis must be confirmed by future assessments of other stress indicators, such as the $\mathrm{CRH}$ level in pregnant women with threatened premature birth. At the same time, our results also indicate that measurements of serum s-IgA level and SOC in the first half of pregnancy may lead to an effective screening of pregnant women who are at a risk of threatened premature birth at an early stage. As such, our findings may be of great significance in terms of identifying the state of stress for pregnant women at an early stage for maternal health. 
The prevalence of threatened premature birth was $25.4 \%$ among the 110 pregnant women who participated in this study. Previous studies have reported the prevalence of threatened premature birth to be $20.0-30.0 \%$ [50] and $26.9 \%$ [51]. Therefore, the prevalence of threatened premature birth in our study is in relatively close agreement with those reported earlier. However, our study does have some limitations, including a small sample size. In addition, there may have been some selection bias as a result of the sample size and low participation rate. To clarify the s-IgA and SOC cut-off points of high sensitivity and specificity, future studies should use a larger population. Since the factors for s-IgA are complex, the results of this study may not refer to a causal relationship between s-IgA and threatened premature birth. Accordingly, detailed observation of more physiological and biochemical factors is required to prove this causal relationship. Nevertheless, our results are the first to show an association between threatened premature birth and the indicators low serum s-IgA and low SOC at an early gestational stage. It can therefore be concluded that sufficient attention should be paid to controlling stress in pregnant women at an early gestational stage.

Acknowledgments The authors would like to thank the participants and medical staff who cooperated in this study. We would also like to thank those who made this study possible; Dr. Akihiro Asamoto at Ishikawa Prefectural Central Hospital, Dr. Minoru Uchida at Uchida Maternity Clinic, and Dr. Tukasa Fukae at Fukae Ledie's Clinic. This study was part of a research supported by a Grant-in-Aid for scientific research from the Ministry of Education, Culture, Sports, Science and Technology for Young Scientists (B) from 2005 to 2006 and from 2007 to 2008 [Nos. $16791379(2005 / 06)$ and $19761686(2007 / 08)]$.

\section{References}

1. Arck PC, Rücke M, Rose M, Szekeres-Bartho J, Douglas AJ, Pritsch M, et al. Early risk factors for miscarriage: a prospective cohort study in pregnant women. Reprod Biomed Online. 2008; 17:101-13.

2. Mancuso RA, Schetter CD, Rini CM, Roesch SC, Hobel CJ. Maternal prenatal anxiety and corticotropin-releasing hormone associated with timing of delivery. Psychosom Med. 2004; 66:762-9.

3. Orr ST, James SA, Prince CB. Maternal prenatal depressive symptoms and spontaneous premature births among AfricanAmerican women in Baltimore, Maryland. Am J Epidemiol. 2002;156:797-802.

4. Rice F, Jones I, Thapar A. The impact of gestational stress and prenatal growth on emotional problems in offspring: a review. Acta Psychiatr Scand. 2007;116:154-5.

5. Orr ST, James SA, Casper R. Psychosocial stressors and low birth weight: development of a questionnaire. J Dev Behav Pediatr. 1992;13:343-7.

6. Clayton JH, Christine DS, Tyan PD, Cleopatra A, Calvin JH, Laura Gl, et al. Stress and blood pressure during pregnancy. racial differences and associations with birthweight. Psychosom Med. 2008;70:57-64.
7. Field T, Yando R, Bendell D, Hernandez-Reif M, Diego M, Vera $\mathrm{Y}$, et al. Prenatal depression effects on pregnancy feelings and substance use. J Child Adolesc Subst Abuse. 2007;17:111-25.

8. Kossakowska-Petrycka K, Walecka-Matyja K. Psychological causative factors in postpartum depression amongst women with normal and high-risk pregnancies. Ginekol Pol. 2007;78:544-8.

9. Riecher-Rössler A, Hofecker Fallahpour M. Postpartum depression: do we still need this diagnostic term? Acta Psychiatr Scand Suppl. 2003;418:51-6.

10. Kiuchi C. Confinement mental disorder (4) which associates well Mental disorder after the delivery and its medical treatment (Part 1) (in Japanese). Jpn J Perinatal Care. 2001;20:966-71.

11. Hobel CJ, Goldstein A, Barrett ES. Psychosocial stress and pregnancy outcome. Clin Obstet Gynecol. 2008;51:333-48.

12. Misra DP, O`Campo P, Strobino D. Testing a sociomedical model for preterm delivery. Paediatr Perinat Epidemiol. 2001;15:110 22.

13. Mackey MC, Williams CA, Tiller CM. Stress, pre-term labour and birth outcomes. J Adv Nurs. 2000;32:666-74.

14. Nordentoft M, Lou HC, Hansen D, Nim J, Pryds O, Rubin P, et al. Intrauterine growth retardation and premature delivery: the influence of maternal smoking and psychosocial factors. Am J Public Health. 1996;86:347-54.

15. Pritchard CW, Teo PY. Premature birth, low birthweight and the stressfulness of the household role for pregnant women. Soc Sci Med. 1994;38:89-96.

16. Petridou E, Salvanos H, Skalkidou A, Dessypris N, Moustaki M, Trichopoulos D. Are there common triggers of preterm deliveries? Br J Obstet Gynaecol. 2001;108:598-604.

17. Goldenberg RL, Hickey CA, Cliver SP, Gotlieb S, Woolley TW, Hoffman HJ. Abbreviated scale for the assessment of psychosocial status in pregnancy: development and evaluation. Acta Obstet Gynecol Scand Suppl. 1997;165:19-29.

18. Messer LC, Dole N, Kaufman JS, Savitz DA. Pregnancy intendedness, maternal psychosocial factors and premature birth. Matern Child Health J. 2005;9:403-12.

19. Lazarus RS, Folkman S. Concepts of stress in life science. In: Psychology of stress-cognitive evaluation and countermeasures (translated by Motoaki H, Haruki Y, Oda M) (in Japanese). Tokyo: Jitsumu Kyoiku Shuppan; 1994. pp. 3-24.

20. Wadhwa PD, Culhane JF, Rauh V, Barve SS. Stress and premature birth: neuroendocrine, immune/inflammatory, and vascular mechanisms. Matern Child Health J. 2001;5:119-25.

21. Hillhouse EW, Grammatopoulos DK. Role of stress peptides during human pregnancy and labour. Reproduction. 2002;124: 323-9.

22. Mancuso RA, Schetter CD, Rini CM, Roesch SC, Hobel CJ. Maternal prenatal anxiety and corticotropin-releasing hormone associated with timing of delivery. Psychosom Med. 2004;66 (5):762-9.

23. Makrigiannakis A, Zoumakis E, Kalantaridou S, Mitsiades N, Margioris A, Chrousos GP, et al. Corticotropin-releasing hormone $(\mathrm{CRH})$ and immunotolerance of the fetus. Biochem Pharmacol. 2003;65:917-21.

24. Hobel CJ, Dunkel-Schetter C, Roesch SC, Castro LC, Arora CP. Maternal plasma corticotropin-releasing hormone associated with stress at 20 weeks' gestation in pregnancies ending in preterm delivery. Am J Obstet Gynecol. 1999;180:257-63.

25. King BR, Smith R, Nicholson RC. The regulation of human corticotrophin-releasing hormone gene expression in the placenta. Peptides. 2001;22:1941-7.

26. Rich-Edwards JW, Grizzard TA. Psychosocial stress and neuroendocrine mechanisms in preterm delivery. Am J Obstet Gynecol. 2005; 192:S30-5.

27. Tsuda A, Takashita Y, Annou N. Effects of life stress on psychobiological responsivity and health behaviors. Research 
accomplishment report (Grant-in-Aid for scientific research from the Ministry of Education, Culture, Sports, Science and Technology in 1995-1997); 1998 (in Japanese). pp. 61-81.

28. Jemmott JB, Magloire K. Academic stress, social support, and secretory immunoglobulin A. J Pers Soc Psychol. 1988;55:803-10.

29. Evans P, Bristow M, Hucklebridge F, Clow A, Walters N. The relationship between secretory immunity, mood and life-events. Br J Clin Psychol. 1993;32:227-36.

30. Stone AA, Neale JM, Cox DS, Napoli A, Valdimarsdottir H, Kennedy-Moore E. Daily events are associated with secretory immune response to an oral antigen in men. Health Psychol. 1994;13:440-6.

31. Yajima J, Tsuda A, Kuwabata T, Yamada S. Relationship between neuropsychiatric immunoendocrinonological changes and mental health using mental health tests (in Japanese). Jpn J Behav Med. 2002;8:17-22.

32. Volkmann ER, Weekes NY. Basal SIgA and cortisol levels predict stress-related health outcomes. Stress Health. 2006;22:11-23.

33. Sjöström H, Langius-Eklöf A, Hjertberg R. Well-being and sense of coherence during pregnancy. Acta Obstet Gynecol Scand. 2004;83:1112-8.

34. Ogawa Y, Nakamura H, Nagase H, Ogino K, Ooshita Y, Tsukahara S. Structural analysis of psychosocial factors involved in the risk for habit-related chronic diseases, with emphasis laid on health locus of control (HLC) and sense of coherence (SOC) (in Japanese). Jpn J Hygiene. 2001;55:597-606.

35. Togari T, Yamazaki Y, Nakayama K, Yamaki CK, Takayama TS. Construct validity of Antonovsky's sense of coherence scale: stability of factor structure and predictive validity with regard to the well-being of Japanese undergraduate students from two-year follow-up data. Jpn J Health Hum Ecol. 2008;74:71-87.

36. Sekizuka N, Nakamura H, Shimada K, Tabuchi N, Kameda Y, Sakai A. Relationship between Sense of Coherence in Final Stage of Pregnancy and Postpartum Stress Reactions. Environ Health Prev Med. 2006;11:199-205.

37. Sekizuka N, Sakai A, Shimada K, Tabuchi N, Kameda Y. Relationship between stress coping ability or the degree of satisfaction with delivery and postpartum depression tendency (in Japanese). Jpn J Matern Health. 2007;48:106-13.

38. Gonçalves LF, Chzaiworapongsa T, Romero R. Intrauterine infection and prematurity. Ment Retard Dev Disabil. 2002;8:3-13.

39. Lohsoonthorn V, Qiu C, Williams MA. Maternal serum C-reactive protein concentrations in early pregnancy and subsequent risk of preterm delivery. Clin Biochem. 2007;40:330-5.
40. Nakao M, Fricchione G, Myers P, Zuttermeister PC, Baim M, Mandle CL, et al. Anxiety is a good indicator for somatic symptom reduction through behavioral medicine intervention in a mind/body medicine clinic. Psychother Psychosom. 2001;70: 50-7.

41. Antonovsky A. The structure and properties of the sense of coherence scale. Soc Sci Med. 1993;36:725-33.

42. Antonovsky A. Solving the mystery about health-stress-coping and health-preserving mechanisms. In: Successful coping and a path towards health (Yamazaki Y, Yoshii K translator) (in Japanese). Tokyo: Yushindo Kobunsha; 2001. pp. 19-39.

43. Yamazaki Y. Salutogenetic theory (a new theory of health) and the concept SOC (sense of coherence) (in Japanese). Qual Nurs. 1999;5:81-8.

44. Erikson M, Lindstrom B. Validity of Antonovsky's sense of coherence scale. A systematic review. J Epidemiol Community Health. 2005;59:460-6.

45. Kaminiwa $S$. Basics of neuropsychiatric immunoendocrinology. In: Kaminiwa S, Kubota M, editors. Mental and physical networks and their architecture from the standpoint of neuropsychiatric immunoendocrinology (in Japanese). Osaka: Shinryo Shinsha; 2000. p. 1-35.

46. Ichikawa S, Tsukano K, Takahashi K, Ueji M, Masuda K. Changes in maternal serum s-IgA level during the course of pregnancy (in Japanese). Perinat Med. 1989;19:713-6.

47. Annie CL, Groer M. Childbirth stress an immunologic study. J Obstet Gynecol Neonatal Nurs. 1991;20:391-7.

48. Shitami C. Study of changes in salivary levels of secretory IgA and stress factors in women during perinatal period (in Japanese). J Jpn Acad Midwifery. 2004;18:29-36.

49. Suzuki K, Minai J, Yamagata Z. Maternal negative attitudes towards pregnancy as an independent risk factor for low birthweight. J Obstet Gynaecol Res. 2007;33:438-44.

50. Amano I, Matsui M, Matsumoto M, Moriyama M. The relationship between the prevalence of threatened premature birth and employment style or life style of pregnant women. The 26th Japan nursing society inclusion-maternal nursing (in Japanese). Japan: Japanese Nursing Association; 1995. p. 135-8.

51. Maternal Tokyo Metropolitan, Center Child Health Service. Statistics of maternal and neonatal care in Tokyo: annual report (in Japanese). Japan: Tokyo Metropolitan Government; 1997. 